\title{
The cannabis debate: Let's do the research
}

My father, who died 4 years ago at the age of 85, was a deeply conservative man. He was a district officer and then a colonial policeman in what was then Northern Rhodesia. When we left in the early 1960s he trained as a solicitor in England and had a predominantly criminal practice. He encountered substance abuse, in all its forms, in all areas of his career. He always believed that the so-called drugs of abuse - including cannabis - should be legalised and subject to the same regulation as alcohol and tobacco. His reasoning came from constant contact with those affected by illegal drugs. He strongly believed that as long as drugs such as cannabis were illegal and, importantly, unregulated - there would be criminal activity associated with their supply and use. Like most sensible people, he could see that the 'war on drugs' was ineffective and causing untold misery to many while bringing immense wealth to a few. Importantly, he also believed that this criminalisation of use and supply led to people who might otherwise have led normal lives landing up as criminals. His opinion was revolutionary for his time and not shared by many of his contemporaries. I have to say that I have always agreed with him.

The recent debate in the $S A M J$ around the legalisation of cannabis ${ }^{[1,2]}$ is timely given the slow pace of attempts at legalising cannabis for medicinal use and also for personal use in different parts of the world. I am not going to get involved in the minutiae of this particular debate, which continues in this current issue. ${ }^{[3-6]}$ Read carefully, the two positions largely converge, both towards the position of legalising cannabis use and supply, albeit with slightly differing opinions on how and when to do this. Having said that, I must congratulate the Central Drug Authority, as a governmental advisory body, for going on record in a public forum to push for a shift in direction in this key area.

Given the free - despite regulation - supply and use of tobacco and alcohol, both indisputably seriously harmful, the caution with which people are approaching the legalisation of cannabis is interesting. But perhaps it is the very knowledge of the harms associated with alcohol and tobacco that is, probably unconsciously, informing this caution? Which brings me to my point. Cannabis will eventually be legalised more widely, at least for medicinal use. However, as pointed out in a recent article in the Medical Journal of Australia, ${ }^{[7]}$ 'cultivation of cannabis for medicinal and scientific purposes needs considered management before it is rolled out as a therapeutic good'. What this article states is that the anecdotal reports from people with intractable illnesses who have had symptomatic benefit from cannabis need further research. Australia's federal parliament has recently amended their narcotic drugs act to allow controlled cultivation of cannabis for medicinal and scientific purposes. In the USA the Drug Enforcement Administration (DEA) announced that it would reach a decision on the legal status of cannabis by July this year, which it is hoped will lower the hurdles that scientists in the USA currently have to jump to do research into cannabis. ${ }^{[8]}$ Both the DEA and the Australian Medical Association - and I am sure most sensible people - believe that we need more research into cannabis.

At present medical use of cannabis is illegal in South Africa, but it is widely used by 'alternative practitioners' who claim to cure a variety of cancers and other serious diseases. I regularly receive emails letting me know where I can access medicinal cannabis locally, and I know of one so-called 'healer' in my local community who was recently arrested for possession of large quantities of medicinal cannabis (to the dismay of those in my leafy suburb who decry the drug lords in our neighbouring informal settlements!). The usual arguments apply - it is 'natural' so cannot be harmful, and the anecdotes of efficacy abound. But at present we have few or no data on the indications, efficacy, safety or dose range of cannabinoids. We also - because there is no regulation and control - have no confirmation that drug constituents are consistent and of high reproducible quality. We don't know how to store the drug to ensure stability, or exactly how it should be prescribed. Given that cannabis is already easily available and will almost certainly be legally available in the not-too-distant future, and that people are already using it 'medicinally', this research is urgently needed and should not be held up in the debates around the harms or otherwise of the substance. And, in this spirit, I would urge government (and large corporates that are involved in selling that truly harmful substance, alcohol) to step up and provide the funds that are needed for research into cannabis - and substance abuse in all its forms.

\section{Bridget Farham \\ Acting Editor}

ugqirha@iafrica.com

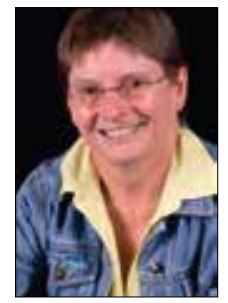

S. Stein D. Position statement on cannabis. S Afr Med J 2016;106(6):569-570. DOI:10.7196/SAMJ 2016.

v106i6. 10863

cott K. Comment on the Central Drug Authority's position statement on cannabis. S Afr Med J 2016;106(6):545-546. DOI:10.7196/SAMJ.2016.v106i6.11036

- Stein D, Manyedi E. Psychoactive substances: Position statement on harm reduction. S Afr Med J 2016;106(9):836. DOI:10.7196/SAMJ.2016.v106i9.11223

4. Stein D, Manyedi E. Position statement on cannabis: A step forwards. S Afr Med J 2016;106(9):837. DOI:10.7196/SAMJ.2016.v106i9.11222

5cott K. Adding to the cannabis debate: Comment on various Central Drug Authority papers. S Afr Med J 2016;106(9):838-839. DOI:10.7196/SAMJ.2016.v106i9.11270

6. Stein D, Manyedi E. Clarifying the position statements of the Central Drug Authority Executive Committee. S Afr Med J 2016;106(9):840. DOI:10.7196/SAMJ.2016.v106i9.11283

Martin JH, Bonomo YA. Medicinal cannabis in Australia: The missing links. Med J Aust 2016;204(10):371-373. DOI:10.5694/mja16.00234

8. Rutkin A. DEA mellowing out on cannabis would make medical research easier. New Scientist 2016, April. https://www.newscientist.com/article/2084036-dea-mellowing-out-on-cannabis-would-makemedical-research-easier/ (accessed 12 August 2016).

S Afr Med J 2016;106(9):833. DOI:10.7196/SAMJ.2016.v106i9.11354 